\title{
Avulsion of the anterior superior iliac spine complicating bone biopsy
}

\author{
A. Stellon, A. Davies and Roger Williams
}

Liver Unit and Department of Radiology, King's College Hospital and School of Medicine and Dentistry, Denmark Hill, London SE5 9RS, UK.

\begin{abstract}
Summary: We present a case report of avulsion of the anterior superior spine following a transiliac crest biopsy, a previously unreported occurrence.
\end{abstract}

\section{Introduction}

Avulsion of the anterior superior iliac spine is well documented in young adults, usually occurring as a result of forcible contraction of the sartorius muscle during a sporting event. In the present report we describe a case of avulsion of the anterior superior iliac spine in a post-menopausal female following a transiliac crest bone biopsy.

\section{Case report}

A 53 year old female with primary biliary cirrhosis of 4 y duration was admitted for iliac crest biopsy as part of the investigation of metabolic bone disease. The biopsy was obtained at the standardized site (Meunier et al., 1971) $2 \mathrm{~cm}$ below and $2 \mathrm{~cm}$ posterior to the anterior superior iliac spine, using an $8 \mathrm{~mm}$ modified Bordier trephine under local anaesthesia and intravenous diazepam sedation. Twenty-four hours later when she departed from the hospital she developed sudden pain around the biopsy site and was unable to bear weight on her right leg. Examination revealed marked tenderness around and anterior to the biopsy site with flexion of the hip and straight leg raising exacerbating the pain. A radiograph of the pelvis (see Figure 1) revealed avulsion fracture of the right anterior superior iliac spine. The patient was placed on bed-rest and given analgesia for the subsequent $2 \mathrm{~d}$ and was gradually mobilized, becoming completely pain free and fully ambulant $12 \mathrm{~d}$ after the event. Subsequent histology of the biopsy revealed no evidence of osteoporosis or osteomalacía.

Correspondence: A. Stellon, B.Sc., M.R.C.P., Liver Unit, King's College Hospital, London SE5 9RS, UK.

Accepted: 25 October 1984

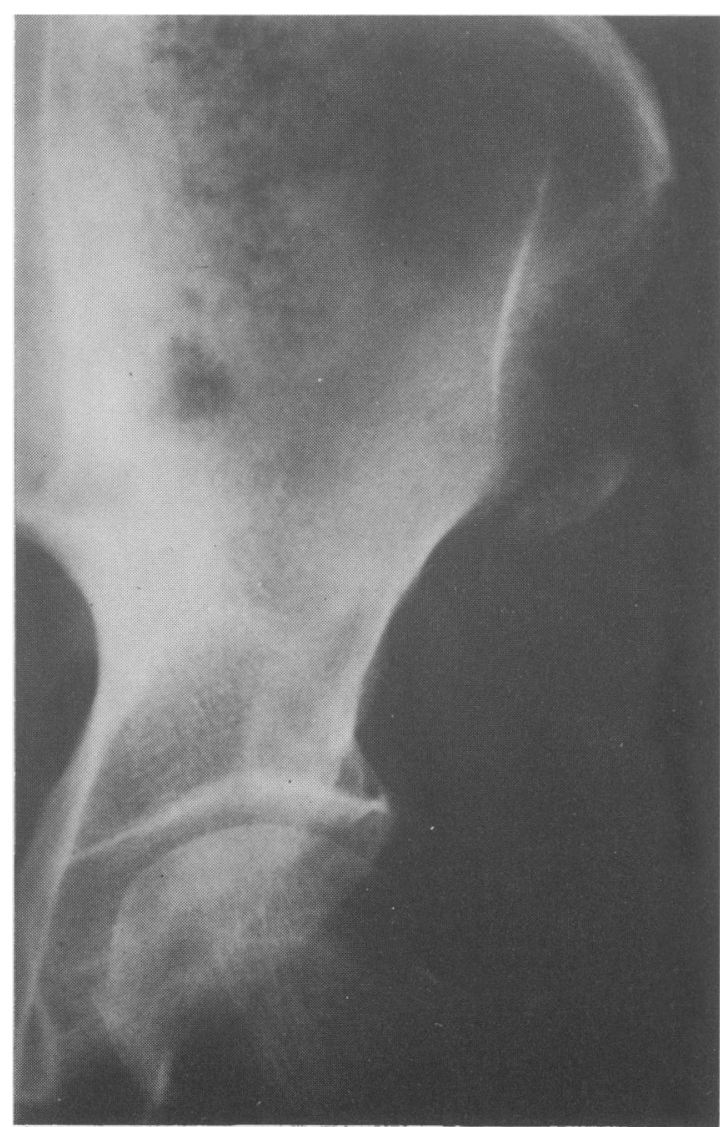

Figure 1 Radiograph of right hip showing an avulsion fracture of the anterior superior iliac spine

C The Fellowship of Postgraduate Medicine, 1985 


\section{Discussion}

Iliac crest biopsies carried out as part of the investigation of patients with metabolic bone disease are usually obtained by a lateral (transiliac) route (Meunier et al., 1971) or a vertical approach (Beck \& Nordin, $1960)$ to the iliac crest, using a trephine of between $3-8 \mathrm{~mm}$ in diameter. A retrospective study of the complications following 14,810 iliac crest biopsies from 14 centres revealed one fracture of the ilium which had occurred in a patient with severe osteomalacia (Duncan et al., 1980). The overall rate of complications including local haematomas, lateral cutaneous nerve neuropathies and pain in excess of $7 \mathrm{~d}$ duration amounted to $0.63 \%$, and complications were more frequent when the larger $8 \mathrm{~mm}$ trephine was

\section{References}

BECK, J.S. \& NORDIN, B.E.C. (1960). Histological assessment of osteoporosis by the iliac crest biopsy. Journal of Pathology and Bacteriology, 80, 391.

DUNCAN, H., RAO, S.D. \& PARFITT, A.M. (1980). Complications of bone biopsy. In Bone Histomorphometry: 3rd International Workshop, Sun Valley, Jee, W.S. \& Parfitt. used. This is not only the first reported case of avulsion of the anterior superior iliac spine following a transiliac crest biopsy, but it occurred in a patient in whom no osteomalacia or osteoporosis was detected histologically; it has to be assumed that the biopsy caused sufficient weakness in that region for the avulsion fracture to result when the patient became ambulant. No other major complication has been experienced in the 170 iliac crest biopsies performed to date in this unit. The use of a smaller trephine may give a lower complication rate but the sample obtained, although adequate for the detection of osteomalacia, may not be sufficient for bone volume measurements.

A.M. (Eds). p. 483. Soc. Nourvelle de Publications Medicales et Dentures: Paris, France.

MEUNIER, P., AARON, J.E., EDOUARD, C. \& VIGNON, G. (1971). Osteoporosis and the replacement of cell populations of the marrow by adipose tissue. Clinical Orthopaedics and Related Research, 80, 147. 